\title{
Refractive Errors in State Junior High School Students in Bandung
}

\author{
Sabila Tasyakur Nikmah, ${ }^{1}$ Raden Maula Rifada, ${ }^{2}$ Putri Teesa Radhiyanti Santoso ${ }^{3}$ \\ ${ }^{1}$ Faculty of Medicine Universitas Padjadjaran, ${ }^{2}$ Department of Ophthalmology Faculty of Medicine \\ Universitas Padjadjaran/National Eye Center, Cicendo Eye Hospital, Bandung, ${ }^{3}$ Department of \\ Physiology Faculty of Medicine Universitas Padjadjaran
}

\begin{abstract}
Background: Uncorrected refractive error is one of the avoidable causes of vision impairment in children and adults. Vision problem in children has been shown to affect their psychological and academic performance. This study aims at identifying and gaining more insights on the characteristic of the refractive errors in state junior high school students in Bandung to avoid uncorrected refractive errors.

Methods: A cross-sectional study was conducted in September-November 2015 in state junior high schools in Bandung, West Java, Indonesia. Sample was selected using multistage random sampling technique. Children were examined using tumbling E examination; then students with visual acuity worse than $6 / 12$ underwent Snellen Chart test, refractometry without pupil dilatation, correction with trial lens, then was followed by direct ophthalmoscopy.

Results: From a total of 435 children who completed all the examination, 80 children (18.39\%) had refractive errors; consisted of 151 eyes (94.38\%) with myopia and 9 eyes (5.62\%) with astigmatism. Refractive errors were found to be more common in female children $(73.7 \%)$ than male children $(26.3 \%)$. Among those with refractive errors, 45 children (56.3\%) did not use any corrective glasses before the examination.

Conclusions: Routine refractive error test in vision screening examination is needed for students. It is equally important to raise more awareness toward eye disease in community. [AMJ.2016;3(3):545-8]
\end{abstract}

Keywords: Children, Refractive Errors, Visual Impairment

\section{Introduction}

Refractive error (RE)is defined as a condition where the eye fails to bring parallel rays of light to focus in the retina that further causes decreasing visual acuity (VA). ${ }^{1}$ According to the data from the World Health Organization (WHO), more than 464 million people in the world have vision loss; with approximately 153 million people have it due to uncorrected refractive error. Uncorrected refractive error is one of the avoidable cause of vision loss in children and adult. $^{2}$

In general, there are two types of eye conditions: emmetropia and ametropia. Emmetropia is a condition with the absence of refractive errors while ametropia is the presence of refractive error. Refractive error could happen when there is a mismatch between the refractive power of the lens and cornea with the axial length of the eyeball. The three types of ametropia are myopia (nearsightedness),hyperopia (farsightedness), and astigmatism. ${ }^{3}$ Therefore, these can be said as eye problems.

Specifically, vision problem in children might affect their psychological and academic performance. ${ }^{4} \quad$ Collaborative Longitudinal Evaluation of Ethnicity and Refractive Error (CLEERE) Study reported that the largest number of new cases of myopia $(18.2 \%)$ occurred at the age of 11 with the majority of them were found in Asians (27.3\%) followed by Hispanics (21.4)\%. ${ }^{5}$ In another study conducted in Australia, prevalence of myopia in the 12-year-old children was also higher than other refractive error. ${ }^{6}$ Similar studies, have not yet been conducted for children in Indonesia, specifically in Bandung. Therefore, this study is intended to identify and to gain more insights on the characteristic of refractive errors among $7^{\text {th }}$ grade state junior high school students in Bandung to avoid uncorrected refractive errors in children.

Correspondence: Sabila Tasyakur Nikmah, Faculty of Medicine, Universitas Padjadjaran, Jalan Raya Bandung-Sumedang Km.21, Jatinangor, Sumedang, Indonesia, Phone: +62811247071 Email: sabilatasyakur@gmail.com 


\section{Methods}

This study was a cross-sectional study conducted from September through November 2015 in several state junior high schools in Bandung, West Java, Indonesia. The subject of this study was $7^{\text {th }}$ graders. The analysis of the study was based on the primary data from vision screening conducted by Community Ophthalmology Division, National Eye Center, Cicendo Eye Hospital, Bandung This study employed multistage random sampling technique to select the school and classes in which this study was conducted. The samples were collected from six state junior high schools from six different regions in Bandung. The inclusion criteria for this study were three folds: registered as a $7^{\text {th }}$ grade in state junior high school student in Bandung in academic year 2015/2016, aged 11-15 years old on the day of the examination, and agreed to participate in the study.

The instrument used in this study was an informed consent, followed by a series of vision screening consisting of tumbling $\mathrm{E}$ examination. Additionally, the students with visual acuity worse than $6 / 12$ underwent Snellen Chart test, refractometry without pupil dilatation, correction with trial lens, then was followed by direct ophthalmoscopy. The refractive errors were expressed as spherical equivalent (SE) - sphere power plus half negative cylinder power. Myopia was defined as SE of at least $-0.50 \mathrm{D}$, hyperopia was defined as SE of $+2.00 \mathrm{D}$ or more, and astigmatism was defined as cylinder of at least
$-0.50 \mathrm{D}$. Myopia was also categorized as mild $(-0.50 \mathrm{D}$ to $-3.00 \mathrm{D})$, moderate $(-3.10$ to -6.00 D) and high (more than $-6.00 \mathrm{D}$ ). The main outcomes gathered were the visual acuity, the correction and the history of correction use. The collected data were then analyzed using the epiinfo software.

Ethical approval was obtained from Health Research Ethics Committee Faculty of Medicine, Universitas Padjadjaran, Bandung. The study permit was obtained from the Kantor Kesatuan Bangsa dan Politik Bandung, the Department of Education and Culture Bandung and the school authorities.

\section{Results}

From the randomized six schools there were a total of 435 subjects consisting of 192 male students and 243 female students from randomly selected classes. From the examination, it was discovered 80 subjects with refractive errors (18.39\%).

Table 1 showed that refractive errors were found more common in female students than male students. This study also showed the classification of refractive errors among state junior high school students according to sex.

Table 2 showed both myopia and astigmatism were found higher in female than male children. From this study, hyperopia case was not found. Mild myopia was found in 118 eyes $(78.15 \%)$, moderate myopia was found in 33 eyes (21.85\%), and no high myopia was found in this study.

Table 1 Demographic Characteristic of Junior High School Students in Bandung, West Java, Indonesia with Refractive Errors

\begin{tabular}{lccc}
\hline & Sex & $\begin{array}{c}\text { Frequency } \\
(\mathbf{n = 8 0} \text { people) }\end{array}$ & Percentage (\%) \\
\hline Male & 21 & 26.3 \\
Female & 59 & 73.7 \\
\hline
\end{tabular}

Table 2 Type of Refractive Errors by Sex among Junior High School Students in Bandung, West Java, Indonesia

\begin{tabular}{lcc}
\hline \multirow{2}{*}{ Characteristic } & \multicolumn{2}{c}{ Type of Refractive Error (n=160 eyes) } \\
\cline { 2 - 3 } & Myopia & Astigmatism \\
\hline Male & $41(25.62 \%)$ & $1(0.63 \%)$ \\
Female & $110(68.75 \%)$ & $8(5 \%)$ \\
Total & 151 & 9 \\
\hline
\end{tabular}


Table 3 Type of Refractive Errors by Sub-classification among Junior High School Students in Bandung, West Java, Indonesia

\begin{tabular}{lcc}
\hline \multicolumn{1}{c}{ Sub-classification of Refractive Errors } & $\begin{array}{c}\text { Frequency } \\
\text { (n=160 eyes) }\end{array}$ & Percentage (\%) \\
\hline Myopia simplex & 81 & 50.6 \\
Astigmatism Myopia Simplex & 9 & 5.6 \\
Astigmatism Myopia Compositus & 70 & 43.8 \\
\hline
\end{tabular}

Table 3 showed that most of refractive error cases in this study was myopia simplex. However, there was only $6.8 \%$ difference between the prevalence of myopia simplex and astigmatism myopia compositus.

Table 4 showed that most of the students with refractive error did not use any correction glasses before the examination. The response for correction on the visual acuity was also checked. Most of the students reached maximum visual acuity; yet two students $(2.5 \%)$ had visual acuity less than $6 / 9$ on Snellen Chart in either one or both eyes after correction. This suggested that these students might have amblyopia or known as lazy eyes.

\section{Discussions}

In this study, it was found 80 subjects with refractive errors (18.39\%). Most children with refractive errors were female $(73.7 \%)$ than in male $(26.3 \%)$.This result mirrored those obtained from studies in Ethiopia, China, Thailand and Cambodia where refractive errors were observed more in female children. However, the difference between female and male children with refractive errors appeared to be higher in Bandung than in those other studies mentioned above. ${ }^{7-10}$ It can therefore be concluded that female children were more vulnerable to refractive errors than male children. Possibly, this condition was associated with the puberty and earlier maturation in female. ${ }^{11}$

A study in Jordan ${ }^{12}$ reported that the common types of refractive errors in children were myopia, then followed by hyperopia and astigmatism. As a comparison, this study exposed that common type of refractive errors in children were myopia (94.38\%) followed by astigmatism (5.62\%), but none hyperopia case. This could be caused by the type of the examination and also the age of sample involved in this study; hyperopia was more common in younger children aged less than 10 years old. ${ }^{13}$ Some children could indeed have a slight hyperopia. However, this may not have been detected through the screening using a Snellen Chart and history taken by the ophthalmologist.

In this study, the term myopia was used for both myopia simplex and astigmatism myopia compositus. Both had been converted with the spherical equivalent to get more general classification on the refractive errors. On the other hand, we also showed the refractive errors based on the sub-classification. It further revealed that the refractive errors in state junior high school students found in this study were myopia simplex $(50.6 \%)$, astigmatism myopia simplex $(5.6 \%)$, and astigmatism myopia compositus (43.8\%). It can then be concluded that actually there was only a slight difference between children who only had myopia and the children who also had astigmatism alongside with their myopia. A study in Karachi ${ }^{14}$ also discovered the same result, astigmatism myopia compositus was the most frequent refractive error in children aged 6-15 years old and followed by myopia with a slight difference between the prevalence.

Most children (56.3\%) did not use any correction before this examination and the rest of the children who have already used correction still need more suitable correction.

Table 4 History of Correction Use among Junior High School Students with Refractive Errors in Bandung, West Java, Indonesia

\begin{tabular}{lccc}
\hline History of Correction Use & $\begin{array}{c}\text { Frequency } \\
\text { (n=80 people) }\end{array}$ & Percentage (\%) \\
\hline Yes & 35 & 43.7 \\
No & 45 & 56.3 \\
\hline
\end{tabular}


From these data, it can be concluded that children were not fully aware of their refractive errors and that they had not yet undergone routine eye examination. This could provoke new insight for the government, schools, parents and doctors. It can be suggested that routine refractive error test in vision screening examination is needed for students, and therefore every school needs to improve their student health unit program. It is important to raise more awareness toward eye disease in community by focusing on early detection of refractive errors and referral procedure.

The limitation of this study was the type of screening that had low sensitivity on detecting children with slight hyperopia. Additionally, the sample in this study was limited to the $7^{\text {th }}$ grade students from six schools in Bandung. For further study, it is recommended that the sensitivity of the screening test should be improved by using other type of vision screening such as using cycloplegic refraction test to detect the refractive errors. This way, the chance of undiagnosed cases such as hyperopia may be reduced. In addition, it would be better to extend more samples to wider group of population, rather than strictly on $7^{\text {th }}$ grade state junior high school students in Bandung.

\section{References}

1. JobkeS, Kasten E,VorwerkC. Theprevalence rates of refractive errors among children, adolescents, and adults in Germany. Clin Ophthalmol. 2008;2(3):601-7.

2. Holden BA. Uncorected refractive error: the major and most avoidable cause of vision loss. Community Eye Health. 2007;20(63):37-9.

3. Optics and Refraction. In: Riordan-Eva P, Whitcher JP, editors. Vaughan \& Asbury's General Ophthalmology. 17th ed. New York: McGraw-Hill; 2008. p. 377-92

4. Fatouhi A, KhabazKhoob M, Hashemi H, Yekta AA, Mohammad K. Importance of
Including Refractive Error Test in School Children's Vision Screening. Arch Iran Med. 2011;14(4):250-3.

5. Kleinstein RN, Sinnott LT, Jones-Jordan LA, Sims J. New Cases of Myopia in Children. Arch Ophthalmol. 2012;130(10):1274-9.

6. Robaei D, Kifley A, Mitchell P. Refractive error and patterns of spectacle use in 12 years old Australian Children. Ophthalmology. 2006;113(1):1567-73.

7. Gao Z, Meng N, Muecke J, Chan WO, Piseth $\mathrm{H}$, Kong A, et al. Refractive error in school children in an urban and rural setting in Cambodia. Ophthalmic Epidemiol. 2012;19(1):16-22.

8. Wu JF, Bi HS, Wang SM, Hu YY, Wu H, Sun W, et al. Refractive error, visual acuity and causes of vision loss in children in Shandong, China. The Shandong Children Eye Study. PLoS ONE. 2013;8(12):1-12.

9. Yared AW, Belaynew WT, Destaye S, Ayanaw T, Zelalem E. Prevalence of refractive errors among shool children in Gondar Town, Northwest Ethiopia. Middle East Afr J Ophthalmol. 2012;19(4):372-76.

10. Yinyong P. Refractive errors survey in primary school children (6-12 year old) in 2 provinces : Bangkok and Nakhonpathom (one year result). J Med Assoc Thai. 2010;93(10):1205-10.

11. Czepita D, Mojsa A, Ustianowska M, Czepita M, Lachowicz E. Role of gender in the occurence of refractive errors. Annales Academiae Medicae Stetinensis. 2007;53(2):5-7.

12. AlBashtawy M, Hameed S, Mansi K, Aljezawi Me, Tubaishat A. Refractive errors among 7-16 year old children. British J Sch Nurs. 2012;7(7):350-54.

13. Kostovska V, Stanković-Babić G, SmiljkovićRadovanović K, Cekić S, Vujanović M, Bivolarević I. Analysis of refractive errors in children aged up to 15 years. Acta Medica Medianae. 2013;52(2):33-40.

14. Ayoob M, Dawood Z, Mirza SA, Ain QU. Refractive errors and their relation to age and sex. Med Channel. 2011;17(2):28-31. 